\title{
Multidecadal Variations of the Effects of the Quasi-Biennial Oscillation on the Climate System
}

Stefan Brönnimann ${ }^{1,2}$, Abdul Malik ${ }^{1,2}$, Alexander Stickler ${ }^{1,2}$, Martin Wegmann ${ }^{1,2}$, Christoph C. Raible ${ }^{1,3}$, Stefan Muthers ${ }^{1,3,4}$, Julien Anet ${ }^{5}$, Eugene Rozanov ${ }^{6,7}$, Werner Schmutz ${ }^{7}$

${ }^{1}$ Oeschger Centre for Climate Change Research, University of Bern, CH-3012, Switzerland

${ }^{2}$ Institute of Geography, University of Bern, CH-3012, Switzerland

${ }^{3}$ Climate and Environmental Physics, Physics Institute, University of Bern, CH-3012, Switzerland

4 now at: German Meteorological Service, Research Center Human Biometeorology, Freiburg, D-79104, Germany

${ }^{5}$ Swiss Federal Laboratories for Materials Science and Technology, Dübendorf, CH-8600, Switzerland

${ }^{6}$ Institute of Atmospheric and Climate Sciences, ETH Zurich, CH-8092, Switzerland

${ }^{7}$ PMOD/WRC Davos, CH-6260 Davos, Switzerland

Correspondence to: Stefan Brönnimann (stefan.broennimann@giub.unibe.ch)

\section{Supplementary Material}
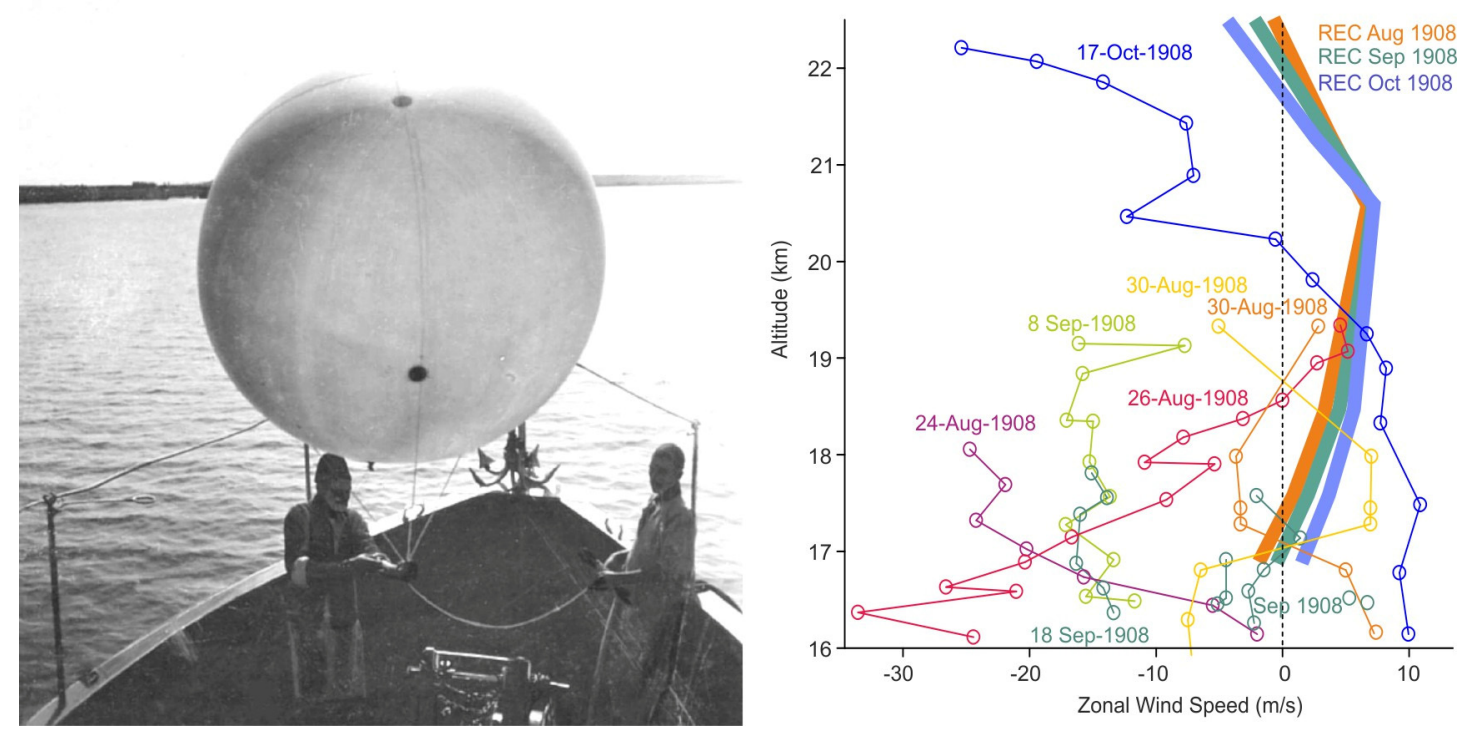

Fig. S1. (left) Registering balloon measurements on Lake Victoria during Berson's East

Africa expedition. (right) Stratospheric zonal wind in the profiles from Berson's expedition. Also indicated are corresponding winds from the reconstructed QBO ("REC"). 


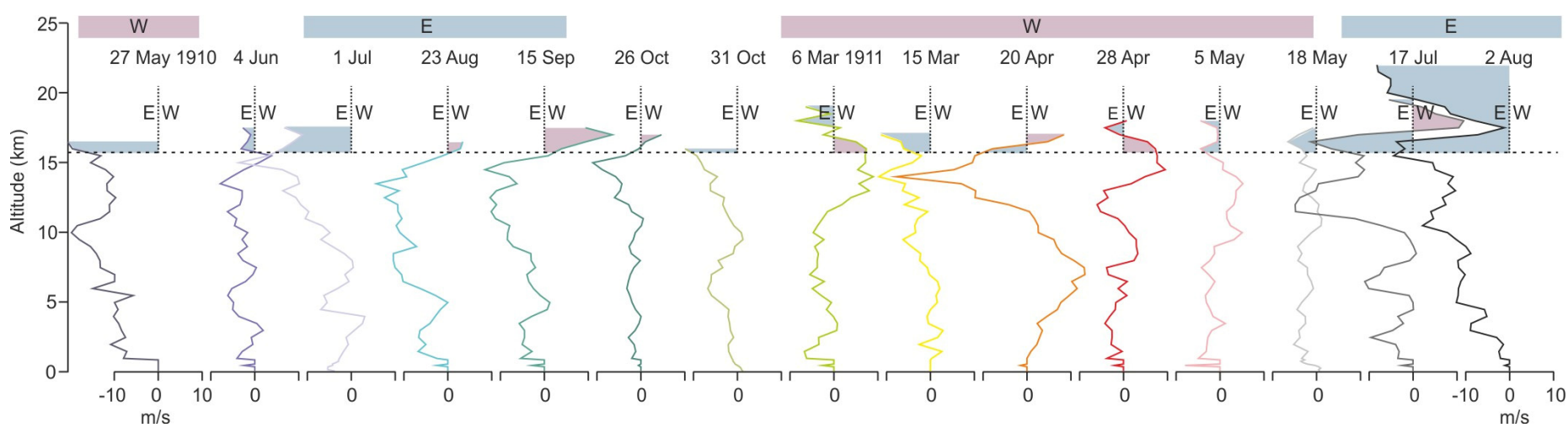

Fig. S2. Profiles of zonal wind from Batavia, 1910-1911. The QBO phase in the top line refers to the reconstructed $\mathrm{QBO}$ at $90 \mathrm{hPa}$.
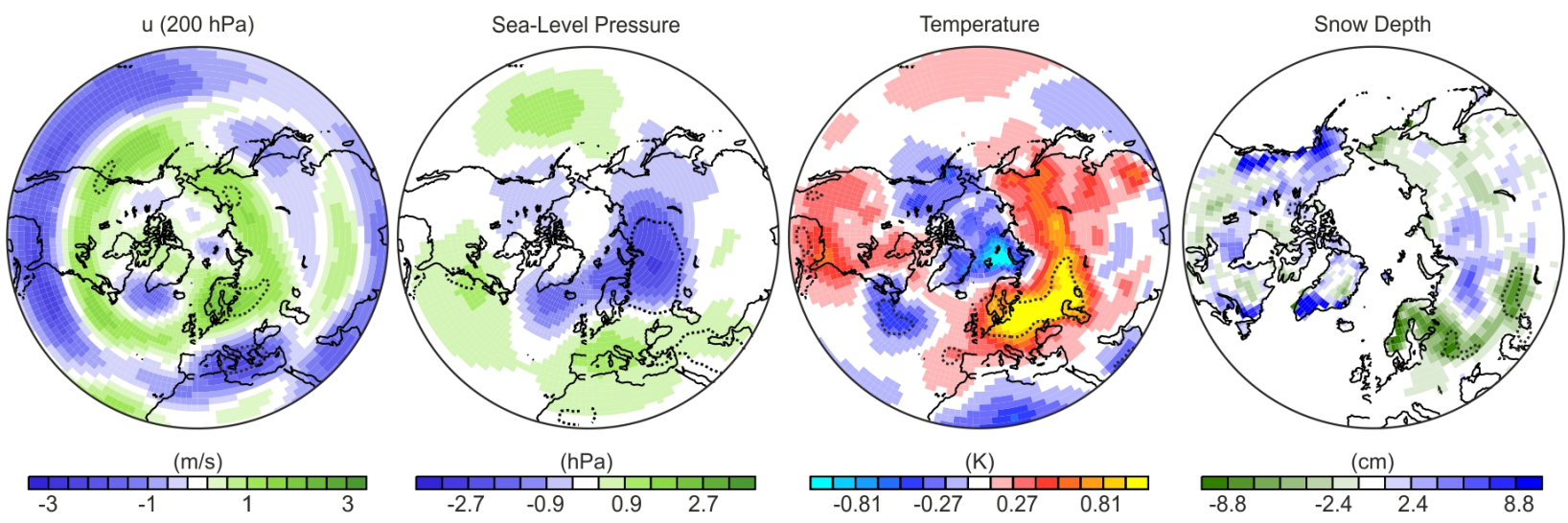

Fig. S3. Composite fields for easterly minus westerly QBO phases of $200 \mathrm{hPa}$ zonal wind, sea-level pressure, SAT, and snow cover. Dashed lines indicate differences that are significant at the $95 \%$ confidence level (t-test).
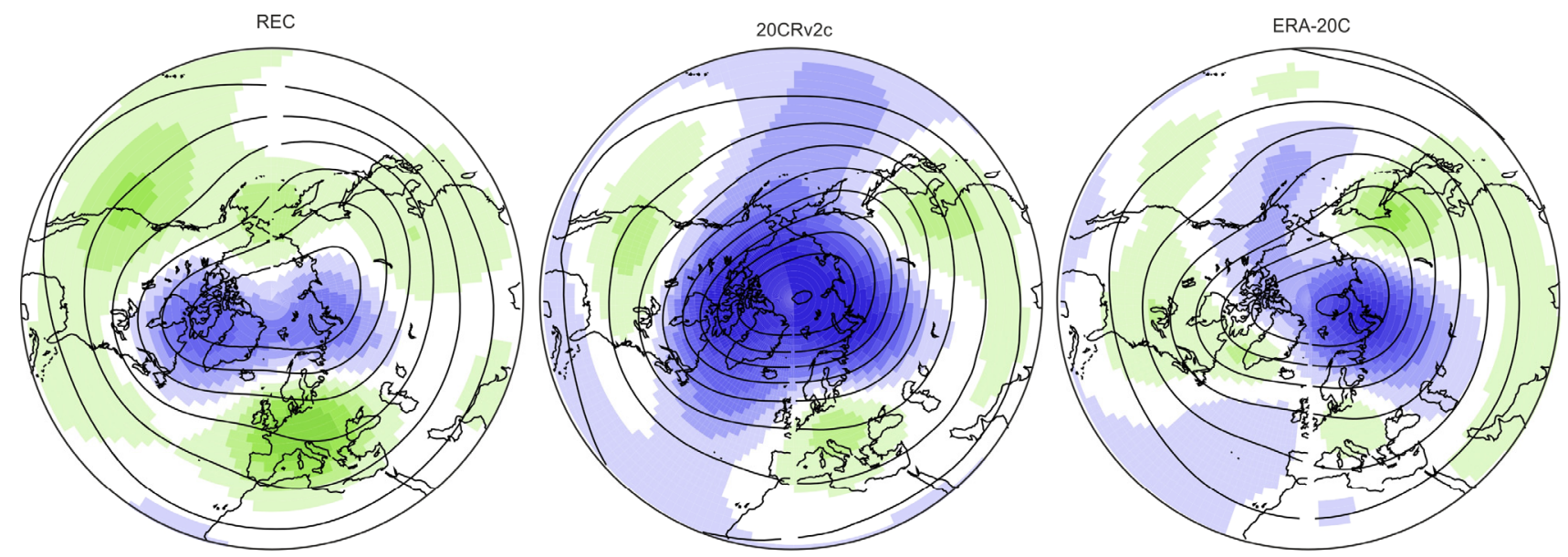

Geopotential Height Difference (gpm)

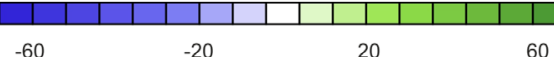

Fig. S4. Composite fields for easterly minus westerly QBO phases for $100 \mathrm{hPa}$ geopotential height in Jan.-Mar., 1908-1957 in reconstructions, 20CRv2c, and ERA-20C. Contours (spacing is $200 \mathrm{gpm}$ ) indicate climatology. 


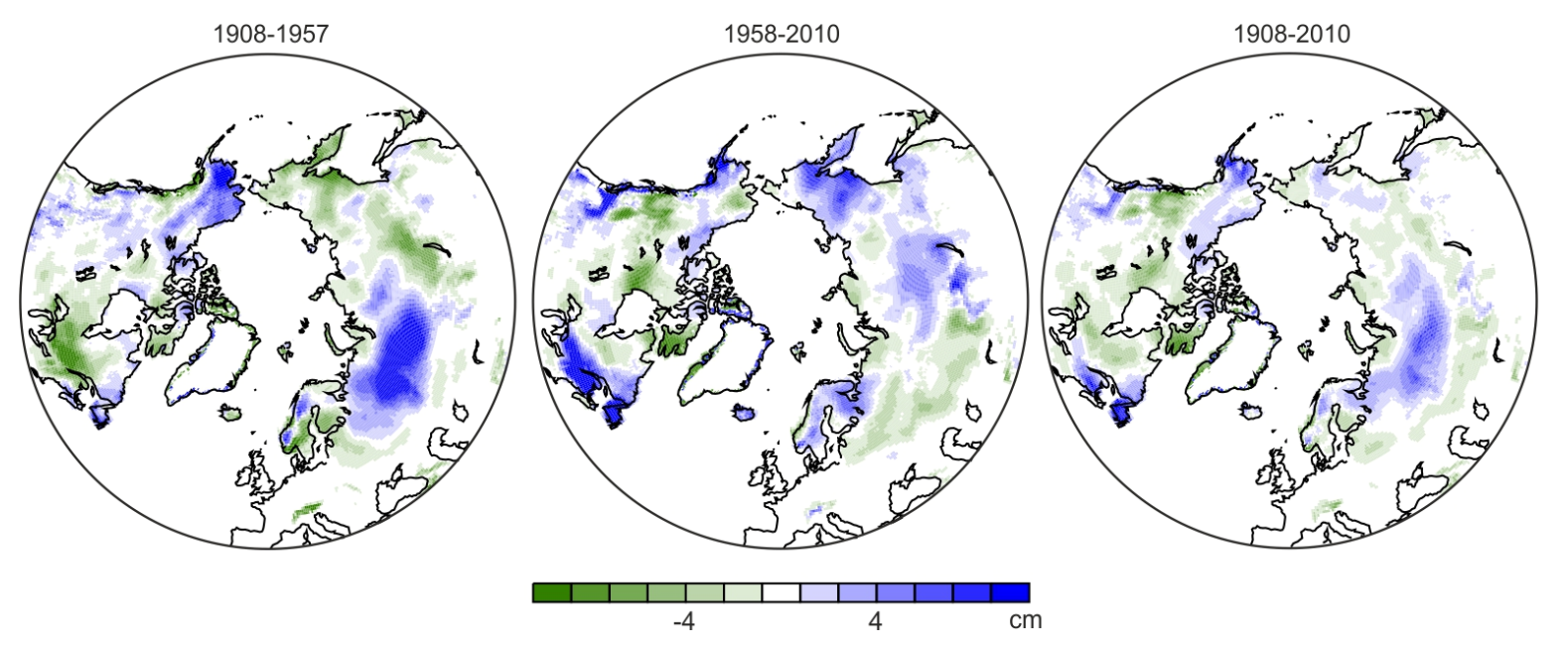

Fig. S5. Composite fields for easterly minus westerly QBO phases for snow depth in ERA20C for (left) 1908-1957, (middle) 1958-2010 and (right) 1908-2010. 

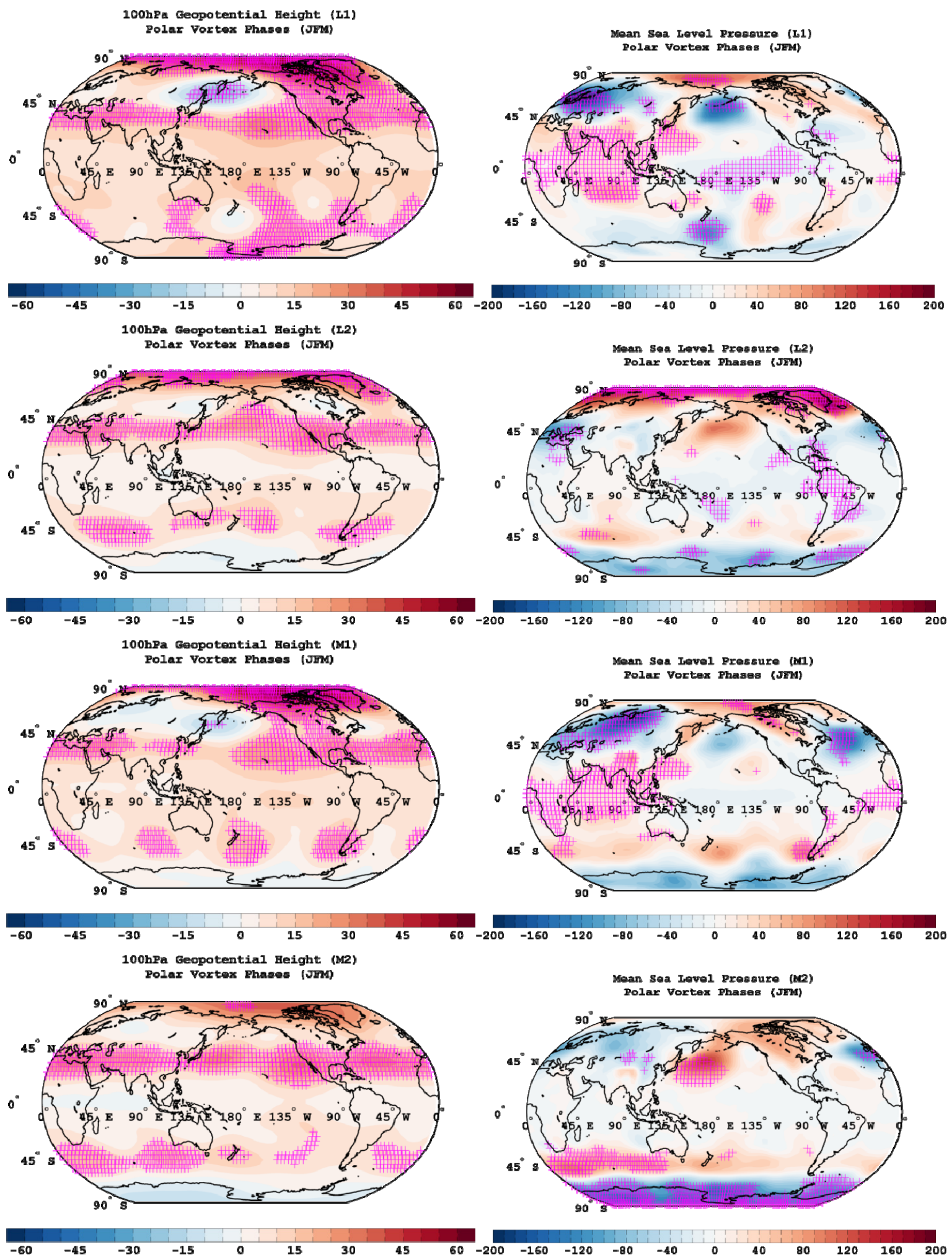

Fig. S6. Composite fields of (left) $100 \mathrm{hPa}$ geopotential height and (right) sea-level pressure for easterly minus westerly QBO phases from the FUPSOL simulations (top to bottom: F13, F14, F23, F24) for Jan.-Mar. Hatching denotes differences that are significant at the $95 \%$ confidence level (t-test). 

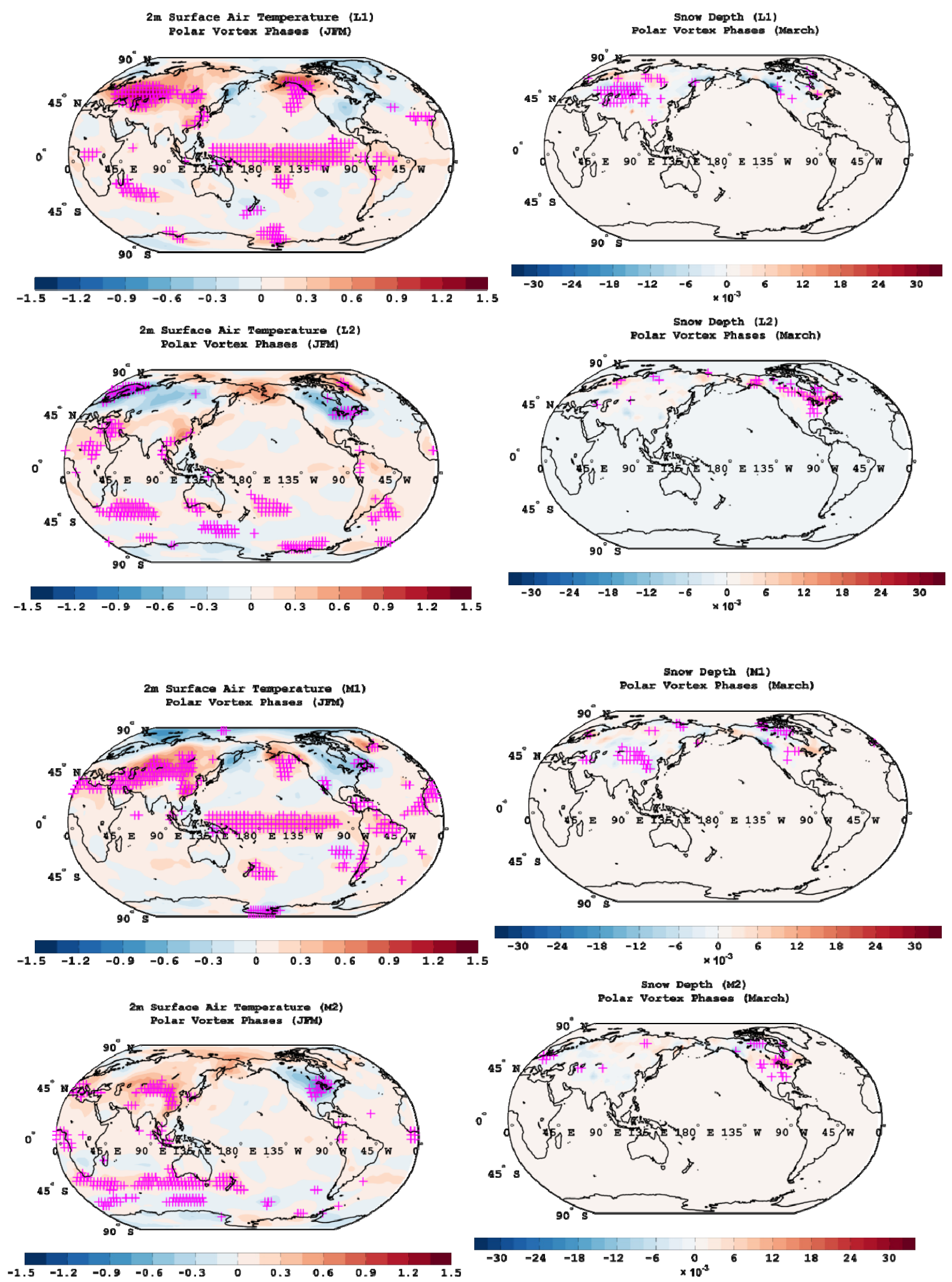

Fig. S7. Composite fields of (left) $2 \mathrm{~m}$ temperature and (right) snow depth for easterly minus westerly QBO phases from the FUPSOL simulations (top to bottom: F13, F14, F23, F24) for Jan.-Mar. Hatching denotes differences that are significant at the $95 \%$ confidence level (t-test). 

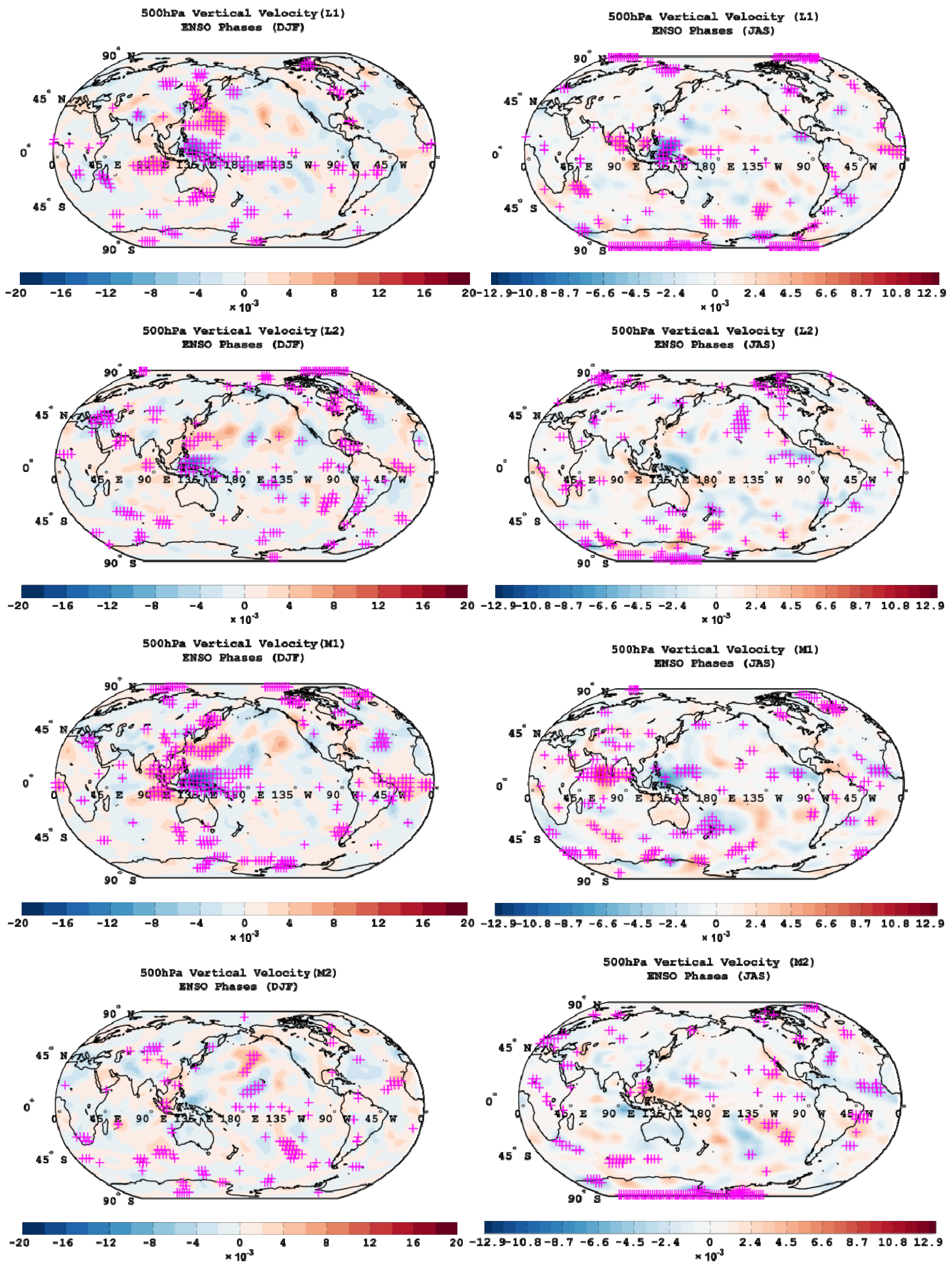

Fig. S8. Composite fields of $500 \mathrm{hPa}$ omega for easterly minus westerly QBO phases from the FUPSOL simulations (top to bottom: F13, F14, F23, F24) for (left) Dec.-Feb and (right) Jun.Aug. Hatching denotes differences that are significant at the $95 \%$ confidence level (t-test). 

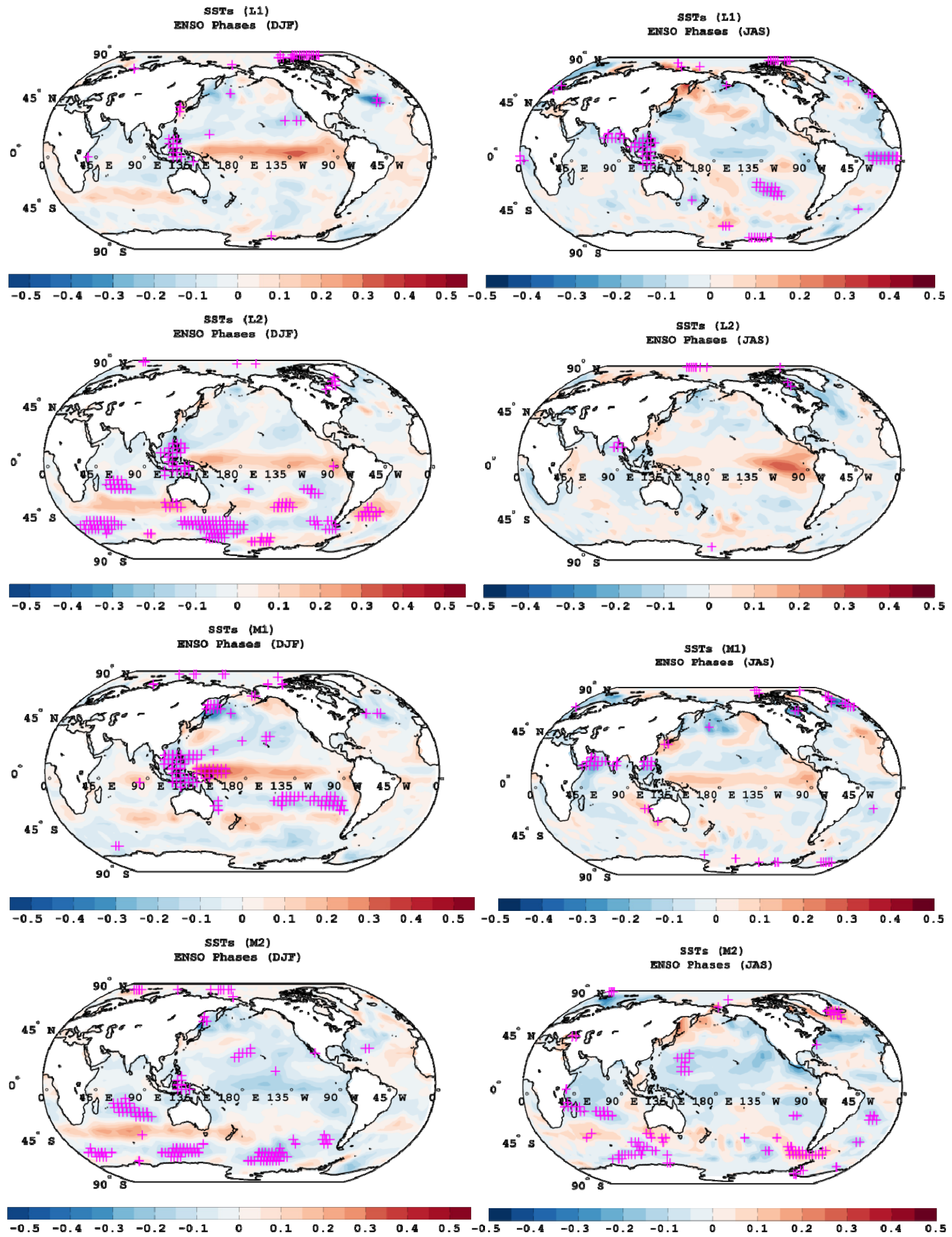

Fig. S9. Composite fields of sea-surface temperatures for easterly minus westerly QBO phases from the FUPSOL simulations (top to bottom: F13, F14, F23, F24) for (left) Dec.-Feb and (right) Jun.-Aug. Hatching denotes differences that are significant at the $95 \%$ confidence level (t-test). 

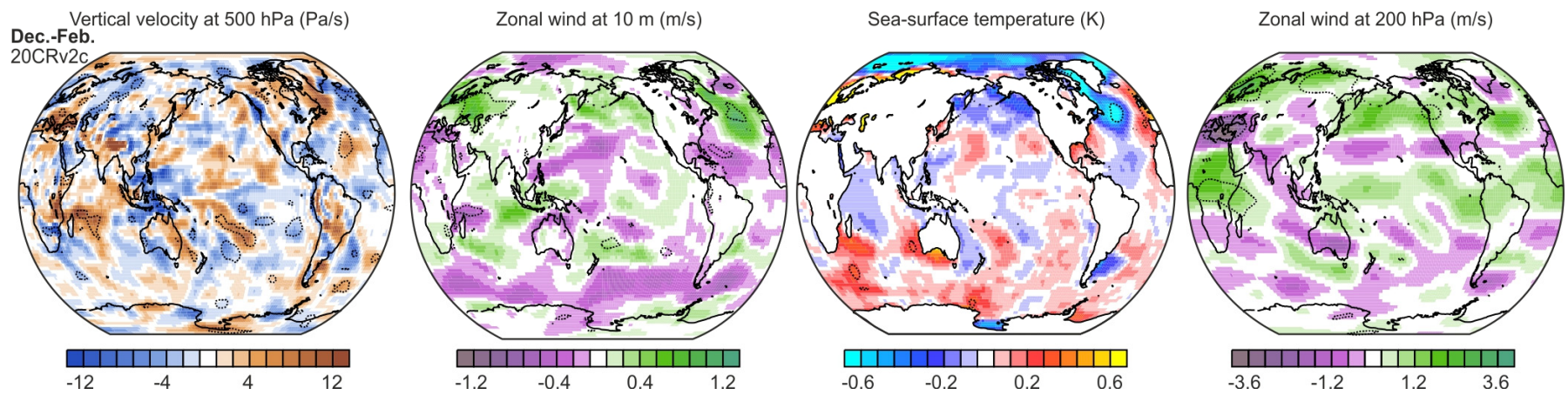

Fig. S10. Composite fields for easterly minus westerly QBO phases for (left) $500 \mathrm{hPa}$ vertical velocity, $10 \mathrm{~m}$ zonal wind, SST, and $200 \mathrm{hPa}$ zonal wind for boreal winter in 20CRv2c. Dashed lines indicate differences that are significant at the $95 \%$ confidence level (t-test). 